\title{
The Innovative Path to Solve the Problem of Urban Ethnic Affairs: The Relief Theory and Its Practical Application
}

\author{
Jing Gao \\ School of Economics and Management, Southwest University, Chongqing, China \\ Email: gaojing0039@126.com
}

Received 28 July 2015; accepted 21 August 2015; published 24 August 2015

Copyright (C) 2015 by author and Scientific Research Publishing Inc.

This work is licensed under the Creative Commons Attribution International License (CC BY). http://creativecommons.org/licenses/by/4.0/

c) (i) Open Access

\begin{abstract}
Based on analyzing the characteristics of urban ethnic affairs problem in the new period, using Coser's the theory of relief valve, combining the sound organization system, solid legal basis and good social reputation and solid grass-roots work experience of Urban Ethnic Affairs department, this paper raises its positioning as the Urban Ethnic Affairs "safety valve", which has a comparative advantage, and improves the "safety valve" in the governance of urban ethnic work ability and promotes to build a harmonious society by the day-to-day management, expanding the work area, adjusting the "safety valve" threshold, establishing of emergency security system, and playing to the leverage effect to uphold the service consciousness.
\end{abstract}

\section{Keywords}

The Relief Theory, Urban Ethnic Problems, The Innovative Path

\section{Introduction}

The realistic background of China's fast economic and social transformation and the deployment and implementation of the national new urbanization strategy lead to the transfer of large rural population to the towns and cities. Multiple ethnic groups are equal in China. The large minority population will run into the cities, resulting in the diversified development and prosperity of the cities. However, the contradictions and conflicts produced by the difference in economic interests, traditional cultures, customs and habits etc. of different ethnic groups are also increasing. Therefore, how to correctly implement the ethnic policies of the party and the state and actively coordinate the urban ethnic relations becomes an important task of urban ethnic work in the new period. According to the theory of safety valve of the Coser, the representative of social conflict school, combined with 
the characteristics of the urban ethnic problem in the new period, we suggest to recognize Department of Urban Ethnic Affairs as the safety valve of urban ethnic work. Then how to effectively play the basic function of the safety valve has the important guidance function and enlightenment for the improvement of the work ability of Department of Urban Ethnic Affairs and realizes the social security and construction of the harmonious society.

This paper mainly includes four parts. The first part explores forms and possible causes of problems of Chinese urban ethnic affairs in the new historical period; the second part summarizes the theory of safety valve and its application in ethnic conflicts; the third part proposes the four advantages of defining the urban ethnic affair department as the "safety valve"; on the basis of the problem exploration and theory analysis, the fourth part explores six measures and policy recommendations for the construction of urban ethnic affair department into the "safety valve".

\section{Reflections and Reasons of Problems of Urban Ethnic Affairs in the New Period}

In the new historical period, the urban ethnic problems mainly include the conflict of economic interests, difficult guarantee of rights and interests, difficult management of the floating population (Li Ping, 2014) [1], mainly because the development of urban ethnic problems brought by the background of globalization and urbanization is diversified and complicated [2]. There are mainly the following four problems of urban ethnic affairs.

i) Affected by domestic and international organizations, ethnic conflicts become more and more obvious in the urban ethnic affairs

There are organizations and power that use ethnic conflicts to provoke ethnic contradictions both at home and abroad. China is a multi-ethnic country composed of 56 ethnic groups. The ethnic groups live together over vast areas, while some live in individual concentrated communities in small areas. Although they have more and more communication, there is a gap among the ethnic groups objectively and they do not understand each other. Especially in recent 10 years there was $3 \times 14$ Incident in Lhasa in 2008 and $7 \times 5$ Incident in Urumchi in 2009 . On March 1 $1^{\text {st }}, 2014$ in Kunming Railway Station civilians were attacked and killed. A series of vicious incidents of violence bring harm to the society and draw the attention of people across the country. These incidents are more or less related to the participation or planning of domestic and international organizations. Now there is very high demand for social stability. Every violent terrorism incident seems to be more outstanding. The more attention the society pays, the higher the destructive power of violent terrorists will be. This paradox is hard to resolve in the modern society.

ii) The excessive ethnic consciousness has become the internal cause of problems of urban ethnic affairs

The urbanization has brought the change of people's behavior patterns, values and interpersonal relationship, and improved the people's comprehensive quality, so that the ethnic groups have a better understanding of each other in the urbanization process. Under the influence of the Han nationality, the sense of ethnic identity of minorities is strengthened, and the related feeling and self awareness of the same ethnic is strengthened, but there is too much emphasis on the characteristics of the ethnic groups and the ethnic consciousness will lead to self defending, anti-foreignism and ethnic hostility, and can even form the invisible ethnic barrier. After the minority groups enter the cities, the gaps in different aspects will make some people psychologically imbalanced, produce the ethnic inferiority feeling, and lead to the imbalance of ethnic relations. Once induced by the external factors, it is easy to cause ethnic conflicts. It can be said that the excessive ethnic consciousness is the social psychological basis of the urban ethnic problems. In recent years, under the background of urbanization and globalization, the ethnic separatists promote the ethnic hatred to the Han nationality in the ethnic areas with ulterior motives, exaggerate the ethnic conflict with the Han nationality and lead to the ethnic conflicts.

iii) The change of the structure of minority population increases the sensitivity of the problems of urban ethnic affairs

The population problem has always been the basic factor affecting the social and economic development of China. Since the 1970 s to the end of the $20^{\text {th }}$ century, our main concern is the number of population. Along with the continuous implementation of China's population policy and the rapid development of social economy, the population urbanization swept across the country. The population structure had a series of changes. The problem of population structure has gradually become the focus of academic circle. In the population structure of minorities, young adults have a high proportion. There are many migrant workers, and the employment pressure is big. According to the data analysis of 2010 Census, from 2000 to 2010, among 17 focused minorities, except Uyghur nationality, the proportion of employment of agricultural population of the rest of the minorities was dropping. 
The decline proportion was 3\% - 20\%. It showed that the minority population who entered the cities and towns for work increased rapidly; in contrast, in the same period, among the employed people in the whole country, the proportion of heads of the party and government institutions increased to $1.77 \%$. The proportion of heads of the party and government institutions of Han, Zhuang, the Korean and Tujia nationality increased. That of other groups dropped. The proportion of heads of the party and government institutions of Uyghur nationality decreased from $0.84 \%$ to $0.47 \%$ in this decade, and the actual number of people decreased from 37,730 to 25,550 , decreasing by 32.3\% [3]. The increase of minority population in cities and towns and the decrease of head of heads of the party and government institutions will increase the pressure on the treatment of problems of urban ethnic affairs, and make minorities feel not trusted and "marginalized, thus causing minorities' hostility to the Han people. It is easy to induce ethnic conflicts.

iv) The characteristics of information spreading in the new media era lead to explosive ethnic problems

Today with the rapid development of Internet and wireless media, the new media centered on the individuals have changed from edge to the mainstream. Te mass media era is gradually replaced by the personal and participatory media era. The multidimensional carriers, trans-time-space information spreading, and the unique clearing power and agglomeration effect in the new media era are changing the moving trajectory of the whole society. For the problems of urban ethnic affairs, the extensive information sources make the information arrangement, identification and control difficult for the management Department of Urban Ethnic Affairs, the public opinion easy to develop in the adverse direction, and the work of national affairs passive [4]. In the new media era, the social ideological trend is more active. A variety of ideas, cultures and points of view communicate and meet, which unprecedentedly expands the space and time of the formation of social ideology. For the sensitive ethnic problems, with the real-time spreading of information in the new media era the multidimensional ideology is easy to be used by some organizations harming the national security and ethnic separatists. They can distort the information, make trouble and cause the explosive ethnic conflicts. It brings many challenges to the work of the management Department of Urban Ethnic Affairs.

\section{The Formation of the Theory of Safety Valve and Its Application Practice in Ethnic Conflicts}

i) The formation of the theory of safety valve

In the sociological research the change of social structure and the change of order are two eternal topics. Talcott Parsons, the main representative of structural functionalism, advocates that a system tends to keep order and balance by itself, and allocation and integration are the most basic process of balance keeping of the system. He gave too much emphasis on the stability of social order, so that he was widely criticized, because in the system the social conflicts could not be seen and he was unable to explain the social change [5]. At this time, the theory of social conflict represented by Ralf G. Dahrendorf and Lewis A. Cose increasingly became the mainstream theory in the sociology study [6]. However, Dahrendorf gave excessive emphasis on the natural and persistent social conflicts that could not be excluded. He could not powerfully explain and analyze all kinds of social phenomenon in reality. Or he gave too much emphasis on the negative effects of social conflicts [7]. Different from Dahrendorf's point of view, in organic function theory Simmel Georg advocates that the social conflict is the process which promotes the unity and unification of social organism and maintains the social system complete. Coser formed his own conflict theory and gave more emphasis on the positive functions of social conflicts [8]. In The Functions of Social Conflicts Coser said: "The conflicts between groups also help with group cohesion and integration. The conflicts help with the integration of relationships [9]." Of course, the social maintaining and integrating function of conflicts have boundary conditions. Through the system construction and reconstruction of rules, the fundamental path of the conflict resolution shall be found. And it is considered that the mechanism of social safety valve is a good mechanism, and conflicts have the function of social safety valve, alleviate and release the social pressure and hostility. So far, Coser's theory of safety valve has been preliminarily formed. Professor Jia Chunzeng, a domestic scholar, vividly describes the theory. The safety valve is a device on the boiler. It can be discharged through the excessive steam, so that the whole device will not be damaged. Similarly, the social safety valve releases the hostility and resentment against society, so it can help to maintain social stability and security.

ii) The application of the theory of safety valve in the study of social governance and ethnic problems

The development of economy and the transformation of the society will cause the gap between rich and poor 
and other social contradictions and conflicts. As a key social conflict, in recent years the ethnic conflict becomes the focus of domestic social contradictions. How to use the theory of safety valve in the social conflicts to solve the problems of urban ethnic affairs in the new period becomes a necessary and feasible research paradigm. For the doctor-patient conflict, Xu Yongjun (2008) proposed how to control and alleviate doctor-patient conflict and construct a harmonious doctor-patient relationship with the theory of safety valve [10]. According to the source and type of the theory of social conflict, Peng Shuangshuang (2009) highlighted the positive functions of social conflicts and made it the system of safety valve which promoted the harmonious society and society construction. Tian Qian (2009) proposed to define Department of Urban Ethnic Affairs as the safety valve to help to develop its function of emergency treatment, resource mobilization and service delivery in the daily management and emergency [11]. For the mass incident of demolition and land acquisition in the urbanization process, Wang Tinglin (2010) introduced the cost-benefit model. With reference of the theory of the safety valve, he proposed to establish the social organization as the safety valve, timely and effectively establish communication between the government and people, monitor the safety valve, and develop the early warning mechanism. Xu Bin (2013) argued that in the late period of transition in China, we should update the safety valve system and mechanism in China in terms of the normalization of the government conducts and the adjustment of power configuration method [12]. Through the literature review, it can be seen that the theory of safety valve is relatively widely used in the application of social governance in China, and many effective measures and suggestions are given, but the operability and social effect remain to be improved.

\section{Advantages of Recognizing Department of Urban Ethnic Affairs as the Safety Valve}

In the new historical development period, Department of Urban Ethnic Affairs itself is recognized as the safety valve of ethnic conflicts, which has the following advantages.

i) With the aid of a sound organization system, develop the basic function of the safety valve

As specified on the $14^{\text {th }}$ Meeting of Government Administration Council of the People's Republic of China early in 1950, in the areas with many ethnic affairs, the commission of ethnic affairs shall be set up. Today, in most cities nationwide ethnic affairs management institutions have been set up, including administrative affairs, policy and law research, economic development, culture and education and other functional departments, basically covering all aspects of the urban ethnic work. A sound organization system can help to avoid the population isolation due to urban and rural differences, ethnic differences and individual differences when the people in the minority areas live in cities, deal with the pressure and obstacles encountered by minorities in the process of integration into cities, and allow the safety valve to dredge, transform and catalyze the discontent and hostility.

ii) According to the legal basis insisted on, provide legal guarantee for the implementation of the safety valve

From the constitution to the basic law of China, from the special administrative regulations issued by the state council to the department regulations formulated by ministries and commissions under the state council, the basic living and the obtaining of rights and interests of minorities in the cities are clearly specified, so that the work of urban ethnic affairs have laws to abide by. Therefore, when ethnic relations are coordinated and dealt with, the urban ethnic affairs are incorporated into the legal governance channel, the governance according to law is insisted on, and legal thinking and legal methods are used to resolve the social conflicts. These are the key to implement the party's ethnic policies, guarantee the legal rights of minorities, and consolidate and develop the equal, united, cooperative and harmonious socialist ethnic relations. They provide the legal protection for the orientation and implementation of the safety valve.

iii) With the help of a good social reputation, strengthen the mass base of the coordination of ethnic affairs with the safety valve

The good mass base is the basic premise of the smooth work of Department of Urban Ethnic Affairs. since its establishment, Department of Urban Ethnic Affairs has been committed to actively give play to propaganda and guidance, coordination and communication, safeguard of rights and interests, stability maintaining and other functions; access to various resources actively, carry out various forms of support and cooperation with the masses and non-governmental organizations, make a significant contribution to the development of cities, and win the broad social identity in the cities. Therefore, with the help of a good social reputation and social identity, the appeal of Department of Urban Ethnic Affairs can be developed, so that the safety valve plays an active role in easing conflicts and resolving contradictions. 
iv) With the aid of grass-roots work experience and ability, reduce the social costs of safety valve in dealing with the conflicts

The concealed, latent and explosive ethnic conflicts make the ethnic work difficult. Department of Urban Ethnic Affairs knows the distribution of minorities in the jurisdiction and is familiar with the habits and customs of minorities. The handling of daily work of minorities for a long time has accumulated valuable experience for it, so that the safety valve can resolve in a timely manner in the forming stage of the incident, and reduce the social costs of handling conflicts.

\section{Measures and Suggestions for the Promotion of the Construction of the Safety Valve of Department of Urban Ethnic Affairs}

i) The fine daily management work allows giving play to the basic function of the safety valve

The public security, industrial and commercial tax, culture and education, health and other fields covered by Department of Urban Ethnic Affairs is the basic events of the city life of minorities, and these departments belong to different government functional departments. It is difficult to coordinate the relationship among the departments. It is suggested that the daily management work shall be fine, accurate and detailed, so as to meet the basic needs of minorities in the cities, eliminate the possible group opposition and contradiction, give play to the safety valve's basic functions of resolving contradictions, dredging the discontent and showing emotion, and lay a foundation for the smooth work of urban ethnic problems.

ii) Actively expand the work area and attach great importance to the construction of the new functions of the invisible safety valve

In addition to the publicity of ethnic policies, safeguarding of the rights and interests of minorities and other traditional work, Department of Urban Ethnic Affairs should attach great importance to the construction of the function of invisible safety valve based on the new binary opposition, rapid development of network, appearance of group structure, application of the new media platform and other characteristics of the times during the fast transformation of economy and society in China. It is suggested to coordinate exchanges and cooperation of ethnic groups with different value orientation through the establishment of information communication platform and public interactive platform; expand the field of work of urban ethnic affairs; increase the new function of information collection, public opinion analysis and early warning and monitoring of the emergency of the invisible safety valve; try to make different ethnic groups and groups form the value identity, identity identification and psychological identity; and build a green channel for minorities' integration into the cities.

iii) Dynamically adjust the threshold of safety valve, determine the starting point of safety valve

Influenced by a variety of powers both at home and abroad, in recent years, urban ethnic conflict happened frequently. In order to maintain the social stability, and insist on the tenet of equal and harmonious development of many ethnic groups in the country, tiny things may be exaggerated as the ethnic problems, thus forming the mass event of emergencies in the society. It indicates that the starting point causing the ethnic conflicts becomes more and more low, and the scope of the threshold of safety valve is expanding. Therefore, it is suggested to dynamically adjust the threshold of safety valve from the regional characteristics, time dimension and cultural background macroscopically and population characteristics, habits and customs, flow characteristics and characteristics of urban distribution of minorities microscopically. For example, in the area where minorities are mixed and concentrated in the cities, the starting point of the threshold of safety valve can be set low. In the areas with the urban social governance ability, the starting point of the threshold of safety valve can be set relatively high. Of course, how to give the starting point of the threshold of safety valve is a technical problem. This paper suggests implementing the system simulation of artificial simulation (ABM) model in the study of artificial society, and determining the threshold according to the simulation diffusion and convergence results [13]. Based on the quantitative research, we can accurately position the alert level of urban ethnic problems and the starting point of safety valve, timely and effectively resolve the ethnic conflicts, and deal with ethnic conflicts.

iv) Establish the emergency guarantee system, improve the response capacity of emergency of the tangible safety valve

The emergency is characterized by big social harm, high loss and serious public crisis. It has drawn the great attention of the government. Dealing with emergencies in the ethnic work is the key link to test the function of safety valve of Department of Urban Ethnic Affairs. This requires a set of perfect emergency systems to guarantee. It is suggested to divide it into advance preparation, response and post assessment; cooperate with the func- 
tional management department of cities [14]; improve the management mechanism of urban ethnic emergency; build the response mechanism of urban ethnic emergency; attach great importance to the remedial work of the urban ethic emergency; build an omni-directional and whole-process urban emergency response mechanism; and improve the emergency response capacity of tangible safety valve in the work of ethnic affairs.

v) Introduce the leverage effect, improve the ability of resource acquisition of safety valve

Seeking more urban resources for minorities is the necessary element to guarantee the development of minorities. Department of Urban Ethnic Affairs is suggested to play the role of bridge and mediation; improve the capability of resource acquisition of safety valve; actively raise, absorb and integrate the urban information, manpower, organization, material and intellectual resources; actively develop the new acquisition channels of resources; and give play to the lever function of safety valve of Department of Urban Ethnic Affairs.

vi) Insist on the service consciousness, improve the service ability of safety valve

The resource acquisition is to better serve the minorities and allow them to enjoy the modern urban civilization. The management department of urban affairs is suggested to mobilize social resources, and change them into the management and service of urban ethnic affairs. It is necessary to insist on the initiative, passionate and thoughtful service consciousness; design the resources obtained to meet the service demand of minority groups who need help and support; and coordinate self identity and urban recognition through the equal enjoying of urban public services and access to development opportunities. This is the important link to test the service supply capacity of safety valve of the management department of urban ethnic affairs.

Through literature review and field survey, this paper has found that the current problems of urban ethnic affairs are as follows. The involvement of foreign organizations and excessive ethnic consciousness lead to ethnic conflicts. The structure change of minority population and the spread characteristic of new media lead to sensitive and explosive problems of urban ethnic affairs. With the advantages of sound organization system, solid legal foundation, good social reputation and rich basic-level experience, the urban ethnic department is considered as the "safety valve" of ethnic problems, which can reduce the social costs of dealing with ethnic conflicts. Finally the paper proposes to promote the construction of "safety valve" of urban ethnic affair department by refining the daily management work, developing work fields, establishing the emergency security system, exerting the just-now effect and focusing on the service consciousness.

\section{Fund}

Fund project: Western Project of the Ministry of Education-Research on the Innovation of Agricultural Production Organization System under the Background of Population Change and Labor Transfer (13XJC630006); National Social Science Fund Project-Research on the Collaborative Path of Evolution of Social Network and Advancement of Agriculture Entrepreneurship in the Transition Period (14CGL029); The Key Project of Basic Scientific Research of Central Colleges and Universities (grant number: SWU1409405, SWU1509126); The Key Project of Urban and Rural Public Cultural Service Collaborative Innovation Center of Southwest University (project number: 15SWUGGFWA01).

\section{References}

[1] Li, P. (2014) Main Problems in the Management Work of Ethnic Affairs in the Powder Mixed Ethnics Areas-Take the Urban Communities in Mudan District, Heze, Shandong Province as an Example. Inheritance, 01, 144-145.

[2] Lin, J.C. (2005) Research on the Urban Ethnic Problems in the Process of Urbanization. Minzu University of China, Beijing.

[3] Ma, R. (2013) Change of Occupational Structure and Cross-Regional Flow of Part of the Employed Population of Part of the Minorities in China-The Initial Analysis on the Data from 2010 Census. Journal of South-Central University for Nationalities (Humanities and Social Science), 06, 1-15.

[4] Long, Y.R. (2013) Management and Innovation of Ethnic Affairs in China in the New Media Era. Study of Ethnics in Guangxi, 02, 22-26.

[5] Hou, J.S. (2001) Course of Western Sociological Theory. Nankai University Press, Tianjin.

[6] Shu, X.B. and Feng, X.T. (2000) The Deconstruction of Structure and Order-Evaluation of the Ideas of Social Change of Spencer, Parsons and Dahrendorf. Journal of Zhejiang, 1, 82-85.

[7] Zhang, W. (2007) The Formation and Development of the Contemporary Western Theory of Social Conflicts. Journal of World Economics and Politics, 5, 117-121. 
[8] Xu, W. (2007) The Application of Coser's Functional Conflict Theory and His Theory of Safety Valve in China. Journal of Guangxi Youth Cadre Institute, 4, 67-69.

[9] Coser, A. (1989) The Functions of Social Conflicts. Translated by Sun Liping, et al., Huaxia Hublishing House, Beijing.

[10] Xu, Y.J. (2008) The Doctor-Patient Conflicts under the Perspective of the Theory of Social Safety Valve. Chinese Health Service Management, 03, 165-166.

[11] Tian, Q. and Zhang, X.L. (2009) Study on the Positioning of Safety Valve of the Department of Urban Ethnic Affairs. Journal of Southwest University for Nationalities: Humanities and Social Sciences, 12, 12-16.

[12] Xu, B. (2013) The Mechanism of Action of Safety Valve of Social Conflicts and its Practice and Advancement in China. Journal of Socialist Theory Guide, 10, 26-30.

[13] Zhang, J. and Li, X.W. (2005) Artificial Society-Agent-Based Social Simulation. Journal of System Engineering, 01, 13-20.

[14] Chen, J. (2013) Collaboration Governance: The Discussion about the Innovation of Ethnic Work of Urban Multi-Ethnic Communities. Journal of Southwest University for Nationalities (Humanities and Social Sciences), 12, 38-45. 